\title{
Assessment of the heat sinking effect of a human hand that holds a flexible phototherapy device for use in Kangaroo Mother Care
}

\author{
Luis Jimenez $^{* 1}$, Luis Vilcahuaman ${ }^{2}$, Jorge Galdos ${ }^{3}$ \\ ${ }^{1}$ Department of Electronics Engineering, Universidad Nacional de San Antonio Abad del Cusco, Cusco, Perú \\ ${ }^{2}$ Engineering Section, Pontificia Universidad Católica del Perú, Lima, Perú \\ ${ }^{3}$ Pediatrics Department, Hospital Regional Cusco, Cusco, Perú
}

\section{A R T I C L E I N F O \\ Article history: \\ Received: 05 April, 2017 \\ Accepted: 03 June, 2017 \\ Online: 19 June, 2017}

Keywords:

Human hand heat transfer

Thermal models

Kangaroo mother care

Heat flow sensors

Phototherapy devices

\begin{abstract}
A B S T R A C T
The heat transfer process from a 6.4 Watt blue light flexible phototherapy mattress to a human hand has been studied. The intended use of the mattress is the provision of neonatal jaundice phototherapy during Kangaroo Mother Care (KMC) or skin-to-skin care. The heat transfer process has been studied with temperature and heat flow sensors inside an expanded-polystyrene spheroid $25 \mathrm{~mm}$ of thickness where the phototherapy mattress's non emitting surface is in contact and folded around the hand while the light radiates outwards, to the polystyrene spheroid. The effective thermal capacitance of the phototherapy mattress was calculated as $3.4 \mathrm{~J} / \mathrm{K}$, the mattress-to-hand thermal conductance was found to be 0.25 $W^{\circ} \mathrm{C}$, the maximum temperature gradient between the mattress and the palm of the hand was $10^{\circ} \mathrm{C}$ and the maximum power absorbed by the hand, $2.5 \mathrm{~W}$. The palm of the hand skinto-core temperature gradient was $0.5^{\circ} \mathrm{C}$. It is expected that when used in $K M C$ only one half of the hand skin surface would be in contact with the phototherapy mattress so that the effective thermal conductance to the hand in this conditions would be $0.125 \mathrm{~W}^{\circ} \mathrm{C}$. Further study is suggested to include sweating effect of the hand.
\end{abstract}

\section{Introduction}

This paper is an extension of the work originally published in 2016 Healthcare Innovation Point of Care Technologies Conference [1], that paper was about the development and thermal assessment of a 1 Watt flexible blue light emitting diode (LED) array designed to apply neonatal jaundice phototherapy simultaneously with Kangaroo Mother Care (KMC) or skin-toskin care, to benefit from both, well stablished, medical interventions in neonatal healthcare, $\mathrm{KMC}$ improves temperature stability of the neonate [2] while blue light irradiance is effective for treating neonatal jaundice [3], some studies like Samra's [4] showed the effectiveness of the simultaneous application. Before starting to use the device on neonates, the authors assessed the thermal performance of this form of phototherapy using two silicone polymer, thermally controlled mannequins, one of a neonate and the other of a mother. Results showed that the power transferred from the phototherapy mattress to the neonatal mannequin was $0.395 \mathrm{Watt}$, and the temperature increase in the contact surface (back of the neonatal mannequin) was $2.75^{\circ} \mathrm{C}$ above its axillari temperature. The average blue light

Luis Jimenez, Av. Huayna Capac 184, Cusco - Peru. Tel +51 984988933

Email:wl_jimenez@yahoo.com phototherapeutic irradiance obtained over the neonatal mannequin's back was $350 \mathrm{uW} / \mathrm{cm}^{2}$, even if this irradiance is not considered intensive phototherapy; it approximately doubles that of white light fluorescent phototherapy devices.

Figure 1 shows the experimental setup with mannequins in [1], it is important to remark that the phototherapy mattress was held over the neonate's back by means of a long bandage acting as a belt around the mother and the baby, with no intervention of the mother's hand. In fact, a real mother would hold the phototherapy device to the baby's back with one hand to make sure the baby don't fall back.

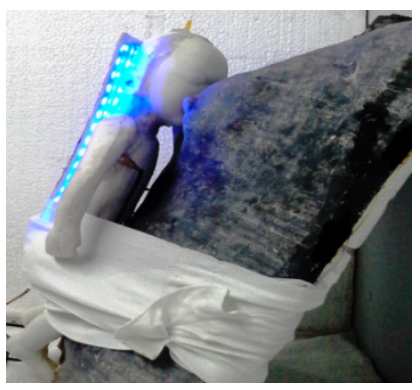

Figure 1: The intended use of the flexible phototherapy mattress in [1] 


\section{Jimenez et al. / Advances in Science, Technology and Engineering Systems Journal Vol. 2, No. 3, 805-811 (2017)}

The present study's aim is to understand how the mother's hand would exchange heat with the phototherapy device; at first one might expect that the hand would act as an extra heat source contributing to the temperature increase of the phototherapy mattress and also that of the neonate. A closer look would make us realize that the mother temperature is physiologically controlled to $37^{\circ} \mathrm{C}$ and that it would have a heat sinking effect when the phototherapy mattress temperature is above the mother temperature.

It is expected that with the hand's sinking effect, the power of the phototherapy mattress could be incremented safely to obtain a higher phototherapeutic irradiance over the neonate's skin. In this work we built a 6.4 Watt phototherapy mattress that has the same dimensions and flexibility as the one described in [1]. Experiments with this mattress around a volunteer's hand and the whole arrangement inside an expanded polystyrene spheroid are performed. Also, Simulink models are developed to obtain the effective thermal conductance from the phototherapy mattress to the human hand.

The thermal conductance we will obtain will allow us to have a design parameter to boost phototherapy irradiance keeping skin temperatures of the mother and the baby in a safe range.

\section{Review of related work}

An example of a medical device emitting light to a tissue, used in contact with the skin is the pulse oximeter; it is for measuring oxygen saturation non invasively, the difference with the phototherapy device of this work is that it only has two diodes and the power dissipated by the device is low compared to the phototherapy mattress of [1]. Medical device regulation agencies test the thermal safety of pulse oximeters over a person's finger that is inside an incubator at $37^{\circ} \mathrm{C}$ [5]. Finally the temperature reached by the pulse oximetry sensor is measured, it has to be at most 4 degrees above body core temperature to get the authorization. The same temperature safety criteria has been applied in [1].

Researchers like Sienkiewicz [7] have quantified the amount of heat that is transferred from a hand submerged in water that is maintained between 37 to 40 degrees. In our case, the phototherapy mattress will not be used underwater, so the conditions for our study are different. Ducharme [6] studies the effect of blood circulation over heat transfer from body limbs to the environment. A review of Taylor [8] provides various thermal heat transfer parameters for hands and feet. An application of hands heat transfer is developed by Heller and Grahn [9], they develop a device that allows to reduce body core temperature rapidly cooling the hands by means of a glove that facilitates perfusion and allows a person to recover faster after exercise and to be able to exercise again.

Heat transfer between a hand and objects has been studied for human-computer interfacing in [10] as short contact time transients. The present work has to consider much longer times because Kangaroo Mother Care sessions last at least two hours as recommended by WHO in [11].

Heat flow from fingers to objects and Peltier pumps have been measured with thin film sensors as in the work of Guiatni and Kheddar [12], we use a similar sensor type as will be described below.
Also, thin film heat flow sensors have been used to measure heat transfer in processes that reached steady state, requiring more than 30 minutes to settle as in [13] where heat flow from human skin or from mannequins to water has been measured, they recommended to apply a thermal compound between the sensor and the material.

In the present work we don't require steady state to occur because modeling will consider heat capacity of the materials. The human hand will be treated as a constant temperature object with a thermal conductance to be determined experimentally.

\section{Materials and Methods}

\subsection{Materials}

The phototherapy mattress of this work is an arrayo of blue light emmitting diodes (LEDs) over an aluminium, duct reparing adhesive tape. Five flexible LED strips are placed in parallel separated $1 \mathrm{~cm}$ from each other over the adhesive tape. The phototherapy mattress dimensions are $10 \times 25 \mathrm{~cm}$ and it weights 50 g. A 2110 Keithley desk multimeter has been used to measure DC current and voltage resulting that the mattress requires 6.4 Watt from a 12 Volt power supply. To assess the heat sinking effect of the hand that holds the phototherapy mattress, a semiadiabatic experimental setup has been designed, it uses a hollow expanded polystyrene spheroid formed by two symmetric halves of $25 \mathrm{~mm}$ of thickness hold together by adhesive tape for the experiments as shown un figure 2 .
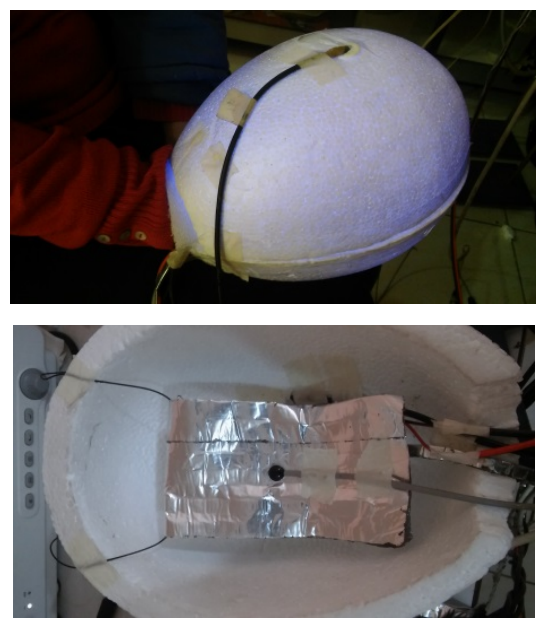

Figure 2: The prolate spheroid for the experiments with phototherapy matress inside

The polystyrene spheroid is prolate, c measures $14 \mathrm{~cm}$, the perpendicular axis a measures $10.25 \mathrm{~cm}$; for the internal surface of the spheroid $\mathrm{c}$ is $11.5 \mathrm{~cm}$ and $\mathrm{a}$ is $7.75 \mathrm{~cm}$ due to the thickness of the spheroid $(2.5 \mathrm{~cm})$. For the experiments, the phototherapy matress is folded in two at the middle of its longest size and sensor are placed inside the spheroid. The weight of the spheroid is $50 \mathrm{~g}$.

The temperature of the phototherapy mattress is measured with a physiological monitor (Star 8000 -Comen Medical), its range is 0 to $50^{\circ} \mathrm{C}$ with $0.1{ }^{\circ} \mathrm{C}$ resolution; the metallic flat surface of the temperature sensor has been fixed to the aluminium tape back surface of the phototherapy matress with a drop of cyanoacrylate adhesive. 


\section{Jimenez et al. / Advances in Science, Technology and Engineering Systems Journal Vol. 2, No. 3, 805-811 (2017)}

A temperature logger based on 5 LM35 sensors records the polystyrene spheroid inner wall temperature in two opposite points, another sensor is inserted in the outer wall of the spheroid as shown in the upper photograph of figure 2. Annother sensor is at the room air temperature. The last temperature sensor is for the experiment with the hand, it is fixed to the skin of the palm of the hand with a drop of cyanoacrylate adhesive. The resolution of this logger is the same as the physiological monitor and its temperature values have been calibrated with the physiological monitor. To measure the heat flow (in Watts $/ \mathrm{m}^{2}$ ) we use a thin film heat flow sensor, model HF4 from Omega Engineering Inc.; it has a sensitivity of $2 \mathrm{uV} /(\mathrm{Watt} / \mathrm{m} 2)$. The microvolt output is measured with a 2110 Keithley multimeter connected to a computer as a voltage logger. In the experiment without the hand, the heat flow sensor has been installed over the inner surface of the spheroid with adhesive tape at the borders, caring not to cover the thermocouple array with the tape as shown in figure 3. For the experiment with the hand, the heat flow sensor has been fixed over the palm of the hand with a drop of cyanoacrylate adhesive in each corner of the flow sensor. In both cases, a thin layer of thermally conductive cream has been applied between the heat flow sensor and the surface of interest.

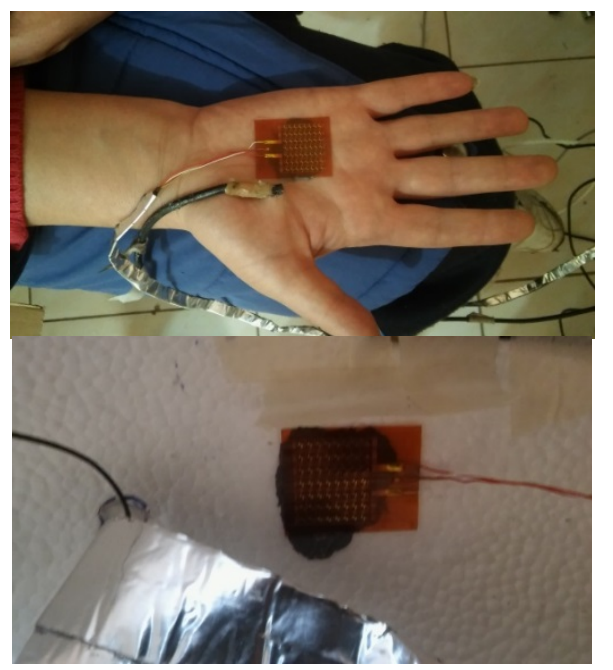

Figure 3: The heat flow sensor HF4 and temperature sensor LM35 fixed to the palm of a hand and to the polystyrene spheroid internal surface.

\subsection{Methods}

We use a thermal modeling method common in power electronics design, specifically the continued fraction or Cauer model [14].

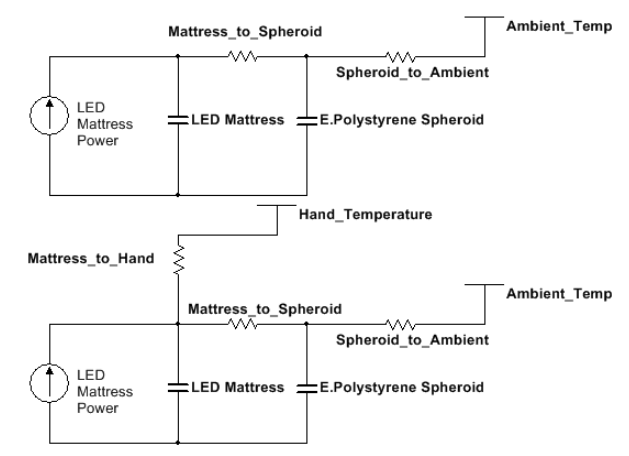

Figure 4: Simplified thermal models for the experiments.
In figure 4 the upper circuit represents the simplified thermal models for the first experiment (without the hand) and the lower circuit represents the experiment with the hand ; the main objective is to determine the thermal conductance between the LED mattress and the human hand.

The first is experiment is to study the thermal behavior of the phototherapy mattress inside the polystyrene spheroid without the hand inside, this is to find the effective thermal specific heat of the mattress, the effective thermal conductance (convective plus radiative) between the phototherapy mattress and the polystyrene spheroid and the effective thermal conductance between the polystyrene spheroid and the surrounding ambient air. The mattress has been kept hanged up inside the polystyerene spheroid and folded in two as shown in figure 5 with the two folded light emmiting surfaces parallel to the hemispheres that form the spheroid that is also kept vertically hanged up by a cotton thread as shown.
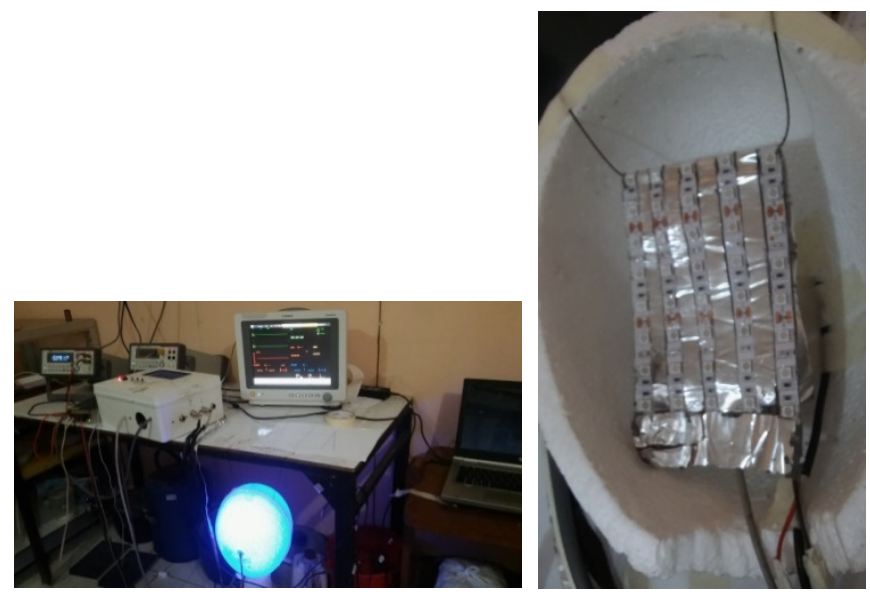

Figure 5: Phototherapy mattress hanged up and folded in two for the experiment without the hand.

The second experiment is the experiment with the hand of a healthy volunteer 48 years old and $70 \mathrm{Kg}$ weight, the total surface area of his hand was measured as $0.024 \mathrm{~m}^{2}$; the two halves of the polystyrene spheroid have been cut in the southern pole to allow the forearm to pass remain outside while the hand is inside the spheroid as shown in figure 6.

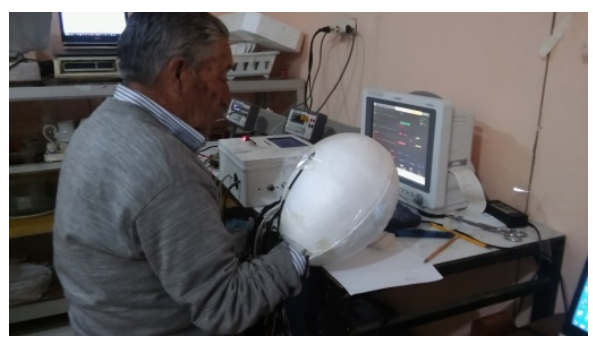

Figure 6: Experimental setup for the experiment with the hand.

\subsection{Conductive, convective and radiating heat transfer:}

- The effective thermal capacity of the phototherapy mattress will be determined in the experiment without the hand; as soon as the mattress is turned on, electrical power minus the radiative power emitted as light by the mattress begins to heat it, increasing the mattress temperature with approximate constant slope the first two minutes. 


\section{Jimenez et al. / Advances in Science, Technology and Engineering Systems Journal Vol. 2, No. 3, 805-811 (2017)}

- The thermal specific heat of expanded polystyerene spheroid is assumed as $1500 \mathrm{~J} /\left(\mathrm{Kg}{ }^{\circ} \mathrm{K}\right)$. With this value and the known weight $(50 \mathrm{~g})$, the spheroid's thermal capacity is $75 \mathrm{~J} /{ }^{\circ} \mathrm{K}$ so the temperature slope related to power is 0.0133 ${ }^{\circ} \mathrm{K} /($ Watt second) that will be used in the to model the experiments.

- Thermal conductance of the spheroid is calculated knowing the thermal conductivity of expanded polysterene assumed $0.035 \mathrm{~W} / \mathrm{m}^{\circ} \mathrm{K}$. The approximate surface of the spheroid is calculated from its dimensions: averaged internal and external dimensions: c_av $=12.75 \mathrm{~cm}$, a $\_$av $=9 \mathrm{~cm}$. As the thickness of the spheroid is $25 \mathrm{~mm}$, the thermal conductance Gspher $=0.354 \mathrm{~W} /{ }^{\circ} \mathrm{C}$; the heat loss of the spheroid to the surrounding air is assumed purely convective assuming low radiative losses, it will be proportional to the temperature difference between the core of the spheroid and the surrounding air temperature. Experimentally, the core of the spheroid temperature is calculated as the average of the inner and outer wall temperatures of the polystyrene spheroid given by the temperature sensors.

- The convective heat loss from the phototherapy mattress to the surrounding polystyrene spheroid is assumed proportional to the temperature difference between the mattress and the spheroid core temperature. The unknown convective thermal conductance will be adjusted by trial and error to make the Simulink model match the results of the experiment without the hand.

- The human hand and the phototherapy mattress are in contact in the second experiment, so, power transfer from the mattress to the hand can be modeled by a constant heat conductance so Pcond= Gcond*(Tmattress-Thand) where power will be in Watts, temperatures in degrees celsius and thermal conductance Gcond in Watt/oC. The effective value for Gcond will be determined so the model matches the results of the experiment with the hand.

\subsection{Simulink model of the experiment without the hand}

Two Simulink models are proposed to compare and adjust some unknown model parameters to match modeling results to the experimental results. The two models use an integrator to model temperature of the phototherapy mattress (output of the integrator); the input to the integrator is the net power received followed by a gain representing the inverse of the heat capacity of the mattress (initially unknown but this parameter will be set according to the results of the experiment without the hand as described in the previous section). Another integrator is used to model the core temperature of the polystyrene spheroid. The Simulink model for the experiment without the hand is shown in figure 7.

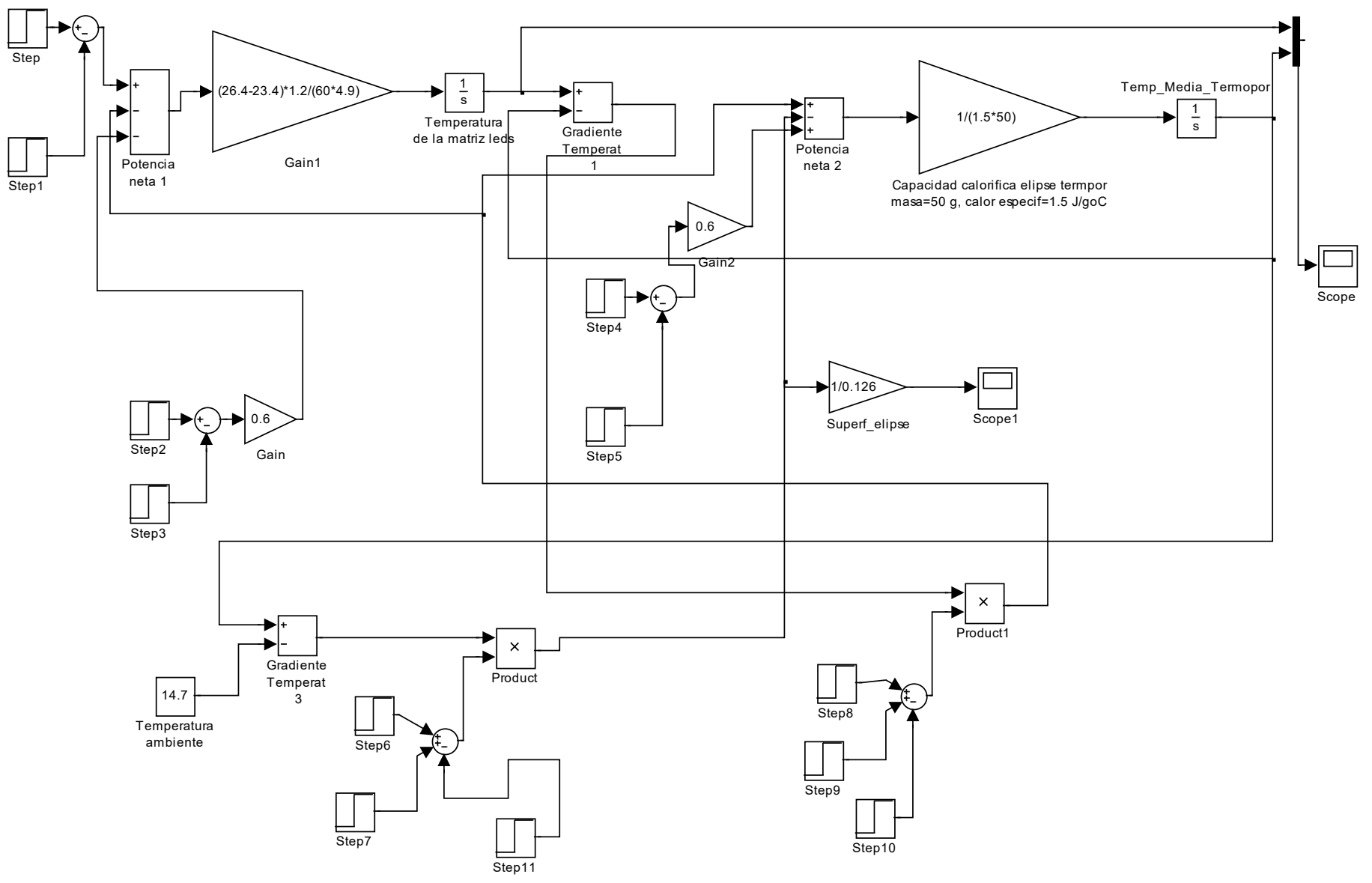

Figure 7. Simulink model for the experiment without the hand. 


\section{Jimenez et al. / Advances in Science, Technology and Engineering Systems Journal Vol. 2, No. 3, 805-811 (2017)}

Step and Step1 sources model the electric power applied to the mattress (6.4 Watt) that starts in zero seconds and finishes in 960 seconds. Part of this power converts to blue light irradiance that goes directly from the LEDs to the polystyrene spheroid. The power corresponding to this irradiance is modeled by Step2 and Step3 sources and has to me substracted from the electrical power because it does not contribute to heating the phototherapy mattress; inversely the same irradiance power modeled by Step4 and Step5 sum directly as power gain to the spheroid. Gain 1 models the inverse of the thermal capacity of the phototherapy mattress, this parameter is adjusted later to match experimental results. The blue light irradiance and the corresponding power are calculated with experimental data from the heat flow sensor described above and the known interior surface area of the spheroid. The upper left integrador is for the mattress temperature and the upper right integrator is for the polystyrene spheroid whose gain at the left represents the inverse of its heat capacitance.

The power loss from the spheroid to the surrounding air is modeled by the temperature gradient with respect to the constant air temperature of $14.7^{\circ} \mathrm{C}$ (in the lower left of figure 7) and the Simulink block product, that models the thermal convective conductance together with Step6, Step7 and Step11 sources (a time variant approach is used to increase the convective conductance that is $0.354 \mathrm{~W} /{ }^{\circ} \mathrm{C}$ from 0 to 480 seconds to $0.454 \mathrm{~W} /{ }^{\circ} \mathrm{C}$ from 480 to 1440 seconds to match experimental data, after this time, conductance returns to the original value of $0.354 \mathrm{~W} /{ }^{\circ} \mathrm{C}$ until the end of the simulated experiment time. Two values of conductance have been necessary because with only one conductance the difference between simulation and experiment mattress temperatures was too high.
The same approach of time variant convective conductance from the phototherapy mattress to the spheroid is implemented by the block Product1 and the Step8, Step 9 and Step 10 sources. The power loss from the phototherapy mattress to the spheroid is proportional to the temperature gradient between the mattress and the spheroid (the substraction of the outputs of both integrators) and the conductance that is adjusted to match the experimental data. It is necessary to state that the phototherapy mattress has been turned off when its temperature approached $50 \mathrm{oC}$ because of the temperature maximum range of the physiological monitor used to record the mattress temperature. The Simulink model has been adjusted to reflect what happened in the experiment at this respect.

\subsection{Simulink model of the experiment with the hand}

The Simulink model for the experiment with the hand is shown in figure 8 . The range of temperatures observed in the experiment with the hand allows the model to be accurate enough with a constant conductance $\left(0.15 \mathrm{~W} /{ }^{\circ} \mathrm{C}\right)$ for the mattress to spheroid and a constant conductance $\left(0.454 \mathrm{~W} /{ }^{\circ} \mathrm{C}\right)$ for the spheroid to ambient; these values are the same that were obtained in the model without the hand. Also, the same thermal capacity of the mattress is used (Gain block entering the integrator). The main difference here is the "hand effect" that is represented by a heat transfer proportional to the temperature gradient between the mattress and the hand, the hand is being represented by constant temperature of $36.5^{\circ} \mathrm{C}$ according to the experiment data. The gain block following the gradient represents the thermal conductance between the phototherapy mattress to the palm of the hand.

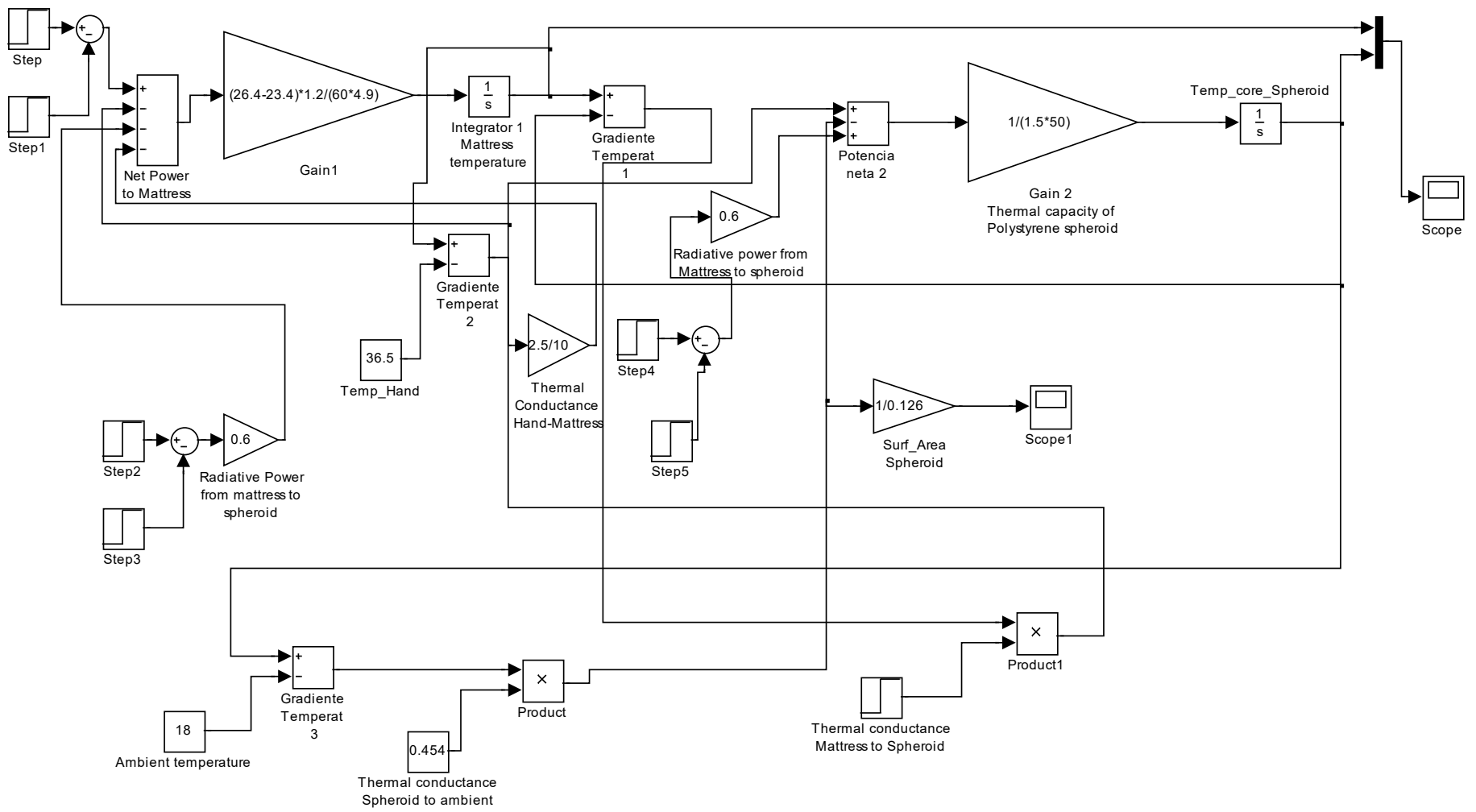

Figure 8. Simulink model for the experiment with the hand. 


\section{Jimenez et al. / Advances in Science, Technology and Engineering Systems Journal Vol. 2, No. 3, 805-811 (2017)}

\section{Results}

\subsection{Results of the experiment without the hand.}

The initial temperature of the mattress and polystyrene spheroid were $18.2^{\circ} \mathrm{C}$ and $14.8^{\circ} \mathrm{C}$ respectively, the electrical power provided to the phototherapy mattress was $6.4 \mathrm{~W}$ during 16 minutes until its temperature achieved $49.5^{\circ} \mathrm{C}$ and power was turned off manually to zero. The exponential curve of the mattress temperature is of the charging capacitor type, the same occurs to the polystyrene spheroid core calculated as described in section 3.3 .

Figure 9 shows the experimental data obtained with the first experiment (wihout the hand): Tmattress, Tcore_spheroid, Heat flow in $\mathrm{W} / \mathrm{m}^{2}$, measured in the inner wall of the polystyrene spheroid, and also, the simulated mattress temperature with the Simulink model with the parameter values adjusted by trial and error to obtain a match between the experiment and simulation.

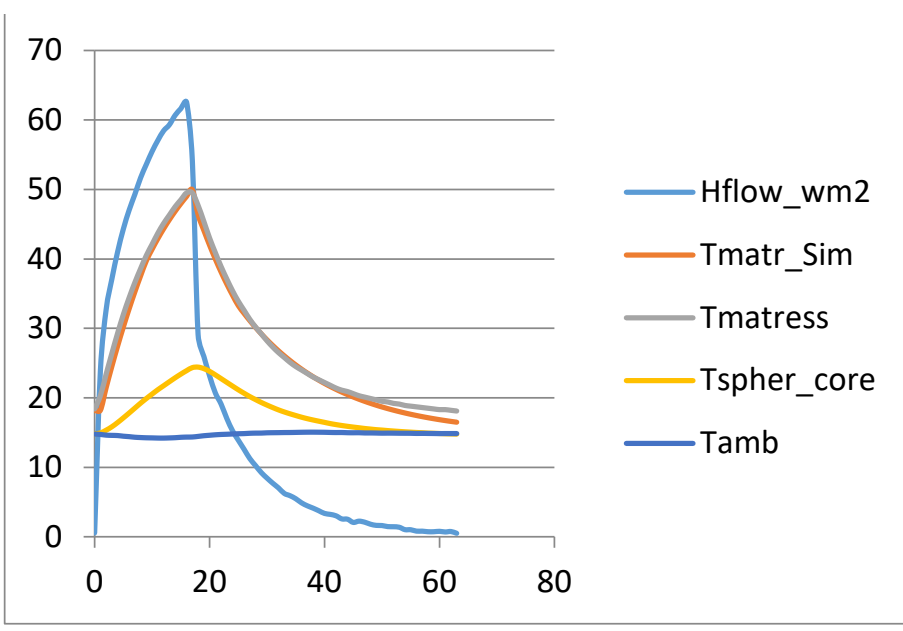

Figure 9. Simulink model for the experiment without the hand.

The first interesting result is the heat flow waveform at the spheroid inner wall showing an immediate transfer of radiating power from the phototherapy mattress because of the step increase from 0.5 to $23 \mathrm{~W} / \mathrm{m}^{2}$, this justifies the radiating power sources in the Simulink model. There is the same type of variation when the phototherapy mattress is turned off.

Next, the phototherapy mattress temperature is showed in grey color overlaps closely the orange color simulated temperature of the mattress, this has been obtained adjusting by trial and error the model parameters to the next values: The thermal conductance of the mattress to the spheroid is not constant trough the simulation time with a value of $0.12 \mathrm{~W} /{ }^{\circ} \mathrm{C}$ the first 8 minutes, then $0.15 \mathrm{~W} /{ }^{\circ} \mathrm{C}$ until the $24^{\text {th }}$ minute and returning to 0.12 until the end of the experiment. An average thermal conductance value of $0.135 \mathrm{~W} /{ }^{\circ} \mathrm{C}$ from the mattress to the spheroid could be used for design purposes in future studies.

Also in the simulation, the thermal conductance from the polystyrene spheroid to the ambient is not constant neither, with values: $0.354 \mathrm{~W} /{ }^{\circ} \mathrm{C}$ and $0.454 \mathrm{~W} /{ }^{\circ} \mathrm{C}$ the same intervals of time indicated above. The thermal capacity for the phototherapy mattress in the simulation is obtained from the first minute of the mattress temperature ramp of the experiment giving a value of 3.4 $\mathrm{J} /{ }^{\circ} \mathrm{K}$ and knowing the $50 \mathrm{~g}$ mass of mattress, the effective specific heat of the mattress results $68 \mathrm{~J} / \mathrm{Kg}^{\circ} \mathrm{K}$. For reference, the calculated thermal capacity of the polystyrene spheroid is $70 \mathrm{~J} /{ }^{\circ} \mathrm{K}$.
The temperature of the mattress during the experiment is limited only because the power has been turned off before it reached $50^{\circ} \mathrm{C}$. It is expected that the hand in the next experiment would be a limiting factor for the phototherapy mattress temperature.

\subsection{Results of the experiment with the hand.}

Figure 10 shows the results of the experiment with the hand with time in minutes. The first minutes are with the mattress turned off, so The heat flow sensor has been fixed with adhesive tape in the borders to the palm of the hand. The negative values mean heat is flowing from the hand to the outside and positive values that heat flows into the hand. The light yellow curve is the heat flow in $\mathrm{W} / \mathrm{m} 2$ and show that while the matress is off, an average heat flow of $3.5 \mathrm{~W} / \mathrm{m} 2$ goes from the hand to the mattress that is folded around the hand, during this time the hand is hotter than the mattress by about $1.5^{\circ} \mathrm{C}\left(34.5^{\circ} \mathrm{C}-33^{\circ} \mathrm{C}\right)$.

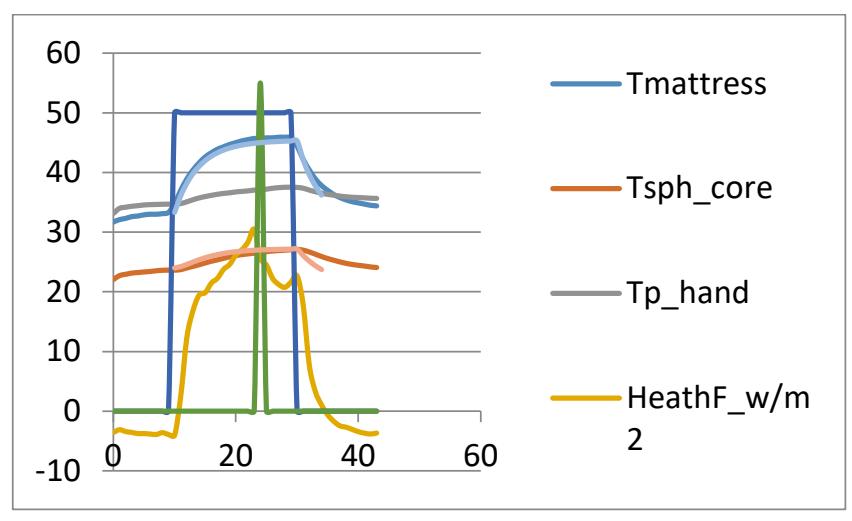

Figure 10. Results for the experiment with the hand.

When the mattress is turned on, the heat flow rapidly changes sign while the mattress's temperature rises but, this time, limited by the temperature of the hand that remains below $37.5^{\circ} \mathrm{C}$ so, the phototherapy mattress reaches $45.8^{\circ} \mathrm{C}$ asymptotically. In the later part of the temperature rising, an occlusion of the brachial artery is produced with the help of the physiological monitor by means of the non invasive blood pressure measurement (NIBP) procedure, this causes a temporal descent of the heat flow to the hand that recovers just before the phototherapy mattress is turned off for the latest part of the experiment. The waveform of the heat flow to the hand during the heating phase is irregular, peaking before the occlusion. The Simulink model for this experiment takes most of the parameters from the previous model without the hand. To match the results of the simulated mattress temperature to the experiment with the hand, the thermal conductance between the mattress and the hand has been found by trial and error to be $0.25 \mathrm{~W} /{ }^{\circ} \mathrm{C}$, there is a close match between simulation and experimental results (curves Tmattress and Tmat_simul). The volunteer reported he felt his hand started to sweat when the mattress temperature rose above $39^{\circ} \mathrm{C}$ and felt thermal discomfort after the NIBP occlusion.

\section{Discussion}

Regarding neonate-mother mannequin pair in kangaroo mother care, in [1] the contact point between the 1Watt phototherapy mattress and the back of a thermally regulated neonatal mannequin was $2.75{ }^{\circ} \mathrm{C}$ above the mannequin 


\section{Jimenez et al. / Advances in Science, Technology and Engineering Systems Journal Vol. 2, No. 3, 805-811 (2017)}

temperature, but now for a $6.4 \mathrm{~W}$ device, the temperature of the palm of a real hand incremented only $0.5^{\circ} \mathrm{C}$ above core temperature $\left(37^{\circ} \mathrm{C}\right)$, so, the real hand has a much higher ability to sink power from the phototherapy device due to blood perfusion in the hand compared to a silicone rubber mannequin. It can be expected that the back of a real neonate as a blood perfused tissue that can sweat would be more able to absorb heat than the mannequin in [1].

Comparing the temperature of the phototherapy mattress in both experiments (Figures 8 and 9), without the hand it rises up to $50^{\circ} \mathrm{C}$ with no limit, contrary to this, in the experiment with the hand, it acts as a heat sink that limits the mattress temperature below $45^{\circ} \mathrm{C}$. The effective thermal conductance of $0.25 \mathrm{~W} /{ }^{\circ} \mathrm{C}$ and the approximate $10{ }^{\circ} \mathrm{C}$ temperature gradient between mattress and hand gives about $2.5 \mathrm{~W}$ absorbed by the hand. But the measured heat flow to the palm of the hand with the heat flow sensor was $25 \mathrm{~W} / \mathrm{m}^{2}$; when considering a hand with $0.024 \mathrm{~m}^{2}$ surface, a total power of $0.6 \mathrm{Watt}$ would be absorbed by the hand, the difference $(2.5 \mathrm{~W}-0.6 \mathrm{~W})$ might be explained by the sweating of the hand.

Our results are in agreement to Taylor [8] that indicates a maximum theoretical transfer of $12 \mathrm{~W}$ to both hands with $1^{\circ} \mathrm{C}$ skin to core temperature gradient (we obtained $2.5 \mathrm{~W}$ to one hand with $0.5^{\circ} \mathrm{C}$ skin to core temperature). We suggest to extend this study to understand the sweating effect, measuring relative humidity inside the expanded polystyrene spheroid. Finally with this results, in Kangaroo Mother Care (KMC) position, the hand of a mother holding the phototherapy mattress would have a contact surface with the mattress of approximately $50 \%$ of the surface in this experiment (only the palm, not the hand's dorsum), so the expected conductance would be $0.125 \mathrm{~W} /{ }^{\circ} \mathrm{C}$ in $\mathrm{KMC}$.

\section{Conclusions}

The effective thermal capacitance of a $6.4 \mathrm{~W}$ phototherapy mattress and the thermal conductance from it to a human hand have been calculated from confined experiments inside a polystyerene spheroid, this thermal model parameters will be used in a future clinical study of heat transfer processes involving a similar phototherapy mattress and real mothers providing Kangaroo Mother Care to neonates requiring jaundice phototherapy.

The ability of a thin film heat flow sensor based on thermocouple arrays to measure radiating heat transfer has been confirmed, it opens the way to use it to study heat transfer processes where clinical radiant warmers are used.

\section{Conflict of Interest}

The authors declare no conflict of interest.

\section{Acknowledgments}

The authors wish to thank Universidad Nacional de San Antonio Abad del Cusco and Hospital Regional Cusco for supporting this study through the project "Effectiveness of blue light irradiance adapted to Kangaroo Mother Care in neonatal jaundice treatment"

\section{References}

[1] Jimenez, L. Vilcahuaman, J. Galdos "Development and thermal assessment of a blue light emitting diode phototherapy device for neonatal jaundice treatment in Kangaroo mother care" in Healthcare Innovation Point of Care Technologies (HI-POCT), 2016 IEEE, Cancún Mexico, 2016.

[2] Ibe O.E., Austin T., Sullivan K., Fabanwo O., Disu E.,Costello A.M. "A comparison of kangaroo mother care and conventional incubator care for thermal regulation of infants $<2000 \mathrm{~g}$ in Nigeria using continuous ambulatory temperature monitoring" Annals of Tropical Paediatrics (2004) 24, 245-251.

[3] Maisels MJ, Kring EA, DeRidder J. "Randomized controlled trial of lightemmiting diode phototherapy" Journal of Perinatology 2007, 27; 565-567

[4] Samra NM1, El Taweel A, Cadwell K. "The effect of kangaroo mother care on the duration of phototherapy of infants re-admitted for neonatal jaundice". J. Matern Fetal Neonatal Med. 2012. Aug; 25(8):1354-7.

[5] JG Webster, Editor. Design of Pulse Oximeters, IOP Publishing Ltd 1997.

[6] Ducharme MB, Tikuisis P. "Role of blood as heat source or sink in human limbs during local cooling and heating" Journal of Applied Physiology 76(5):2084-94, 1994.

[7] Sienkiewicz ZJ1, O'Hagan JB, Muirhead CR, Pearson AJ "Relationship between local temperature and heat transfer through the hand and wrist" Bioelectromagnetics. 1989;10(1):77-84

[8] Taylor NA, Machado-Moreira CA, van den Heuvel AM, Caldwell "Hands and feet: physiological insulators, radiators and evaporators" JN Eur J Appl Physiol. 2014 Oct;114(10):2037-60

[9] Heller H. Craig, Grahn Dennis A. "Enhancing Thermal Exchange in Humans and Practical Applications " Disruptive Science and Technology. Volume 1, Number 1, 2012. Mary Ann Liebert, Inc.

[10] Boron K, Kos A. "Thermal model of selected parts of human hand and thermal touch screen for the blind" Metrol. Meas. Syst., Vol. XIX (2012), No 3, pp. 593-602.

[11] World Health Organization "Kangaroo Mother Care, A practical guide" Department of Reproductive Health and Research, 2003

[12] Guiatni M, Kheddar A. "Theoretical and Experimental Study of a Heat Transfer Model for Thermal Feedback in Virtual Environments" 2008 IEEE/RSJ International Conference on Intelligent Robots and Systems.

[13] Mak, L.; Farnworth, B.; Ducharme, M.; Kuczora, A.; Sweeney, D.; Uglene,W.; Hackett, P.; Potter, P. "Thermal protection measurement of immersion suit comparison of two manikins with humans pilot study report" Technical Report 2010-04 . National Research Council Canada.

[14] Kunzi R. "Thermal design of power electronic circuits" Proceedings of the CAS-CERN Accelerator School. CERN, Geneva 2015 